Research Paper

\title{
aMSH inhibits adipose inflammation via reducing FoxOs transcription and blocking Akt/JNK pathway in mice
}

\author{
Guannv Liu ${ }^{1}$, Meihang Li ${ }^{1}$, Muhammad Saeed ${ }^{1}$, Yatao Xu ${ }^{1}$, Qian Ren ${ }^{1}$ and Chao Sun ${ }^{1}$ \\ ${ }^{1}$ College of Animal Science and Technology, Northwest A\&F University, Yangling, Shaanxi, 712100, China \\ Correspondence to: Chao Sun, email: sunchao2775@163.com \\ Keywords: $\alpha \mathrm{MSH}$, adipose, inflammation, FoxOs, Akt/JNK \\ Received: March 22, $2017 \quad$ Accepted: April 07, $2017 \quad$ Published: April 27, 2017 \\ Copyright: Liu et al. This is an open-access article distributed under the terms of the Creative Commons Attribution License \\ 3.0 (CC BY 3.0), which permits unrestricted use, distribution, and reproduction in any medium, provided the original author and \\ source are credited.
}

\section{ABSTRACT}

\begin{abstract}
Alpha melanocyte stimulating hormone ( $\alpha \mathrm{MSH})$ abates inflammation in multiple tissues, while Forkhead box proteins $O$ (FoxOs) stimulate inflammatory cascade. However, the relationship between $\alpha M S H$ and FoxOs in adipose inflammation remains unclear. In this study, we used LPS-induced inflammation model, attempted to interpret the function of $\alpha \mathrm{MSH}$ in inflammation and the interactions with FoxOs. Results indicated that upon inflammatory situation, the secretion of $\alpha \mathrm{MSH}$ and the expression of its receptor MC5R were greatly decreased, but FoxOs expressions were elevated. After the treatment with $\alpha \mathrm{MSH}$, LPS-induced adipose inflammation together with FoxOs expressions was significantly reduced. Conversely, when Foxo1, Foxo3a or Foxo4 overexpressed in aMSH treated inflammatory mouse model, all the anti-inflammatory impacts of $\alpha$ MSH were found disappeared. We further studied the mechanisms by which aMSH exerts its anti-inflammatory impacts and how FoxOs reverse aMSH's function. Foxo4 was found as a negative regulator for MC5R transcription in aMSH inhibited inflammation. Moreover, a negative role was found of aMSH in regulating both Akt and JNK signal pathways by observing the enhanced the anti-inflammatory impacts of pathway-specific inhibitors with $\alpha \mathrm{MSH}$ treatment. Our findings demonstrate $\alpha \mathrm{MSH}$ plays a key role in the prevention of adipose inflammation and inflammatory diseases by downregulating Akt/JNK signal pathway and negatively interacting with FoxOs, which brings up $\alpha \mathrm{MSH}$ as a novel candidate factor in the adipose anti-inflammation process in obesity.
\end{abstract}

\section{INTRODUCTION}

Obesity and Type 2 diabetes are accompanied with chronic inflammation, which are involved in many disorders and diseases in human $[1,2]$. Chronic inflammation in adipose tissues promotes the development of ectopic fat deposition, and is essential for healthy adipose tissue expansion and remodeling [3, 4]. Excess lipid deposition exactly contributes to immune cell proliferation, pro-inflammatory cytokines releases, macrophage accumulation in adipose tissue, perivascular adipose tissue disturbance, acceleration of subsequent macrophage infiltrating into white adipose tissue, and susceptibility to obesity, insulin resistance or Type 2 diabetes [5-10]. Fatty acid synthesis is also considered to be indispensable for adipose chronic inflammation [11]. Recent studies show that adipose tissue inflammation and fibrosis are the pathological process linking to obesity, and external stimuli hypoxia and free fatty acids exacerbate inflammation [12, 13]. M1 macrophages release proinflammatory cytokines that result in insulin resistance, while M2 macrophages secrete anti-inflammatory cytokines to protect against obesity and inflammation, thus macrophage polarization status control immune process [14-16]. Therefore, deciphering the molecular mechanism of adipose inflammation leads to development of a novel therapy for human inflmmatory diseases, such as obesityinduced insulin resistance and diabetes.

Alpha melanocyte stimulating hormone $(\alpha \mathrm{MSH})$, is produced by proopiomelanocortin (POMC) neuron, which is one of neuronal populations of arcuate nucleus (ARC) in brain. $\alpha \mathrm{MSH}$ reduces food intake and energy storage, and increases energy expenditure of the peripheral tissues and organs via interacting with its receptors $[17,18]$. As 
an endogenous neural immunomodulatory peptide, $\alpha \mathrm{MSH}$ is involved in nerves system-endocrine-immune network. $\alpha \mathrm{MSH}$ or its analog inhibits nitric oxide (NO) production, and reduces lipopolysaccharide endotoxin (LPS) or TNF $\alpha$ induced inflammation [19]. Previous studies have showed that $\alpha \mathrm{MSH}$ abolishes tumor necrosis factor $\alpha$ (TNF $\alpha$ )-induced NF- $\kappa \mathrm{B}$ activation in nasal epithelial cells, and inhibits hypothalamic inflammation response to IL-1 $\beta$ as well $[20,21]$. LPS has been shown to induce inflammation in adipocytes, myocytes and hepatocytes $[19,22] . \alpha \mathrm{MSH}$ is obviously resistant to inflammatory response, and it blunts LPS-induced inflammation by controlling NF- $\mathrm{KB}$ activation and $\mathrm{Akt} / \mathrm{FoxO} 1$ pathway in skeletal muscle [23]. $\alpha \mathrm{MSH}$ in adipose tissue is known for its antioxidant and anti-inflammatory properties, which can abate LPS-induced inflammation and obesity [24, 25]. Previous studies in our lab revealed that $\alpha \mathrm{MSH}$ accelerates preadipocyte proliferation by alleviating ER stress-induced Leptin resistance, and it promotes fatty acid oxidation in adipose tissues together with transcription factor Foxc2 [26, 27]. In addition, transcription factors Foxo1, Foxo3a, Foxo4 and Foxo6 in mammals have been found to promote inflammatory cascades in adipose tissues and maintain immune system homeostasis [28-31]. However, whether the transcription factors FoxOs are involved in $\alpha \mathrm{MSH}$ exerting pivotal effects on adipose inflammation and the molecular mechanism remain to be elucidated.
In this study, we demonstrated that $\alpha \mathrm{MSH}$ inhibited LPS-induced adipose inflammation. Moreover, we showed that FoxOs transcriptional inhibition and phosphorylation blocking of Akt/JNK signal pathway were involved in $\alpha \mathrm{MSH}$ inhibited adipose inflammation. The results might serve as theoretical basis for inflmmatory diseases.

\section{RESULTS}

\section{$\alpha$ MSH attenuates LPS-induced adipose inflammation by inhibiting FoxOs expressions in mice}

To investigate the effects of $\alpha \mathrm{MSH}$ on LPS-induced inflammation, we intraperitoneally injected LPS into male mice. We noted that LPS significantly increased the serum protein levels of pro-inflammatory cytokines IL-1 $\beta$ and IL-6 $(P<0.05)$, while decreased the levels of anti-inflammatory cytokines IL-4 and IL-10 $(P<0.05)$ (Figure 1A), indicating that LPS-induced inflammation model was successfully established. LPS decreased the serum level of $\alpha \mathrm{MSH}$ and the mRNA expression of its receptor $M C 5 R$ by approximately $45 \%(P<0.05)$ (Figure $1 \mathrm{~B}$ and $1 \mathrm{C})$. We observed significant increases in Foxol, Foxo3a and Foxo 4 mRNA levels of white adipose tissue $(P<0.05)$, but no effects on Foxo6 mRNA level (Figure 1D). In LPS-induced inflammation model, injection of
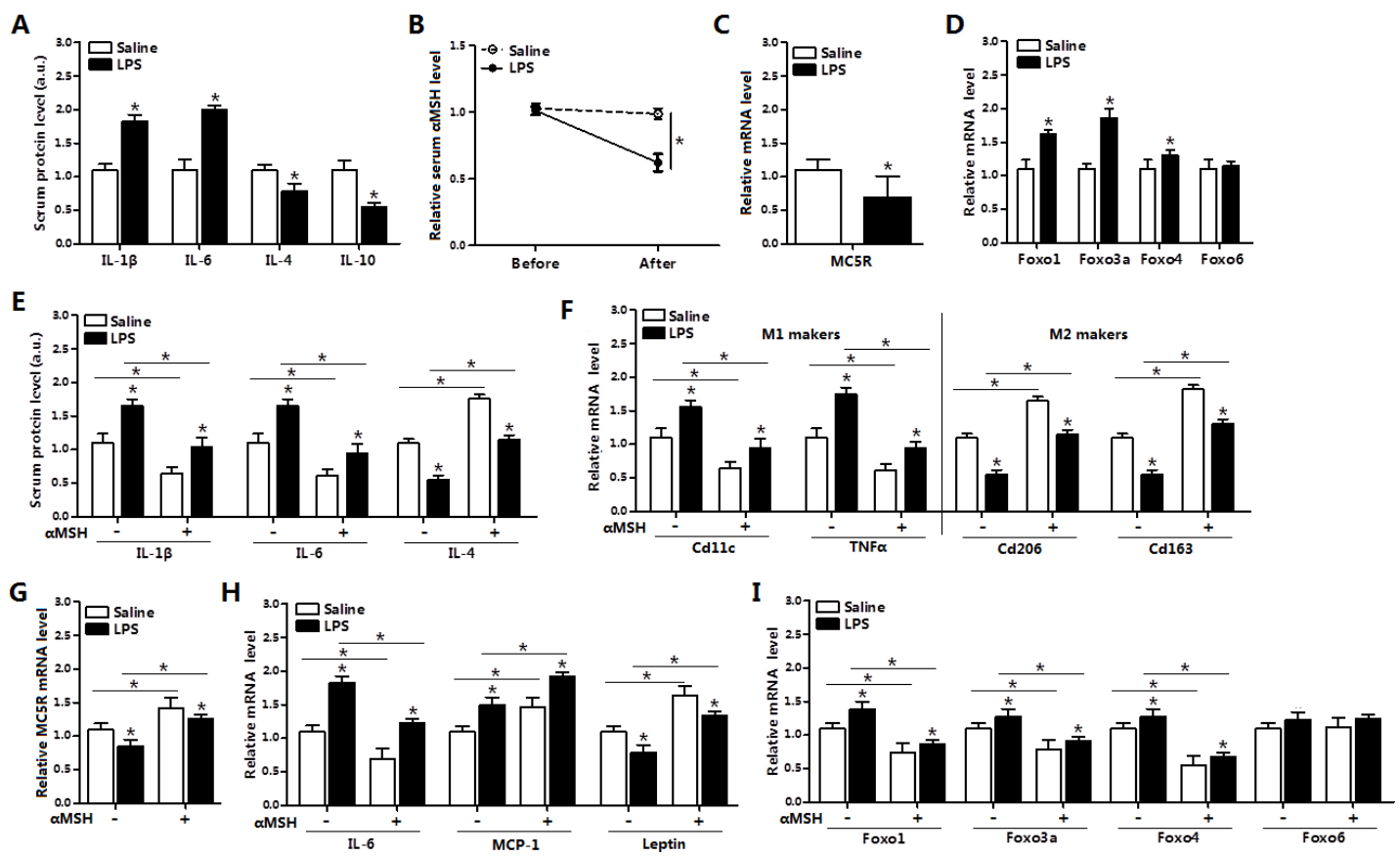

Figure 1: $\alpha$ MSH weakens LPS-induced adipose inflammation by inhibiting FoxOs expressions in mice. (A) Serum protein levels of IL-1 $\beta$, IL-6, IL-4 and IL-10 after mice with LPS or saline intraperitoneal injection (n=6). (B) Measurement of serum $\alpha$ MSH level before and after LPS or saline intraperitoneal injection $(n=6)$. Epididymis white adipose tissue was isolated after intraperitoneal injection with LPS or saline, then mRNA levels of MC5R (C), Foxo1, Foxo3a, Foxo4 and Foxo6 (D) were detected (n=6). Base on the LPS/saline injection, mice were injected with another $500 \mathrm{nM} \alpha \mathrm{MSH}$, then further detected for relative serum protein levels of IL-1 $\beta$, IL-6, IL-4 (E) and mRNA levels of M1, M2 markers (F), MC5R (G), IL-6, MCP-1, Leptin (H), Foxo1, Foxo3a, Foxo4 and Foxo6 (I) in white adipose tissue $(\mathrm{n}=6)$. Values are means $\pm \mathrm{SD}$. vs. control group, ${ }^{*} P<0.05$. 
$\alpha \mathrm{MSH}$ significantly decreased mice serum protein levels of IL-1 $\beta$ and IL-6 $(P<0.05)$, but increased the level of IL-4 $(P<0.05)$ (Figure 1E). In addition, $\alpha \mathrm{MSH}$ markedly decreased the mRNA levels of $I L-6, M C P-1$ and M1 macrophage makers $C D 11 c$ and $T N F \alpha(P<0.05)$, while increased the mRNA levels of Leptin and M2 macrophage makers $C D 206$ and $C D 163(P<0.05)$ (Figure $1 \mathrm{~F}$ and $1 \mathrm{H})$. These results indicated that $\alpha \mathrm{MSH}$ weakened LPS-induced adipose inflammation. To investigate the mechanism by which $\alpha \mathrm{MSH}$ exert this function, the expression of $\alpha \mathrm{MSH}$ receptor MC5R and members in FoxOs family were detected. In accordance with the trend in inflammatory cytokines, $\alpha \mathrm{MSH}$ reversed the mRNA level of $M C 5 R$ reduced by LPS $(P<0.05)$ (Figure $1 \mathrm{G})$. Meanwhile, $\alpha \mathrm{MSH}$ inhibited the mRNA levels of Foxo1, Foxo $3 a$ and Foxo 4 induced by LPS $(P<0.05)$ (Figure 1I). These data indicated that $\alpha \mathrm{MSH}$ blocked LPS-induced adipose inflammation in mice by inhibiting FoxOs expressions.

\section{FoxOs reverse the inhibition of $\alpha M S H$ on adipose inflammation in mice}

To further investigate how FoxOs act on $\alpha \mathrm{MSH}$ inhibited adipose inflammation, we injected pAd-Foxo1, pAd-Foxo3a or pAd-Foxo4 to mice and then treated with hormone $\alpha \mathrm{MSH}$. It was observed that $\alpha \mathrm{MSH}$ reduced and pAd-Foxo1 lifted Foxo1 mRNA level in mice adipocytes as expected $(P<0.05)$ (Figure $2 \mathrm{~A}) . \alpha \mathrm{MSH}$ individually enhanced the mRNA level of its receptor MC5R $(P<0.05)$, which was slightly inhibited after pAd-Foxol treatment. In mice serum, we found decreases in IL-1 $\beta$ and IL-6 contents $(P<0.05)$, while increases in IL-4 and IL-10 contents after $\alpha \mathrm{MSH}$ treatment $(P<0.05)$, but these effects were reversed by Foxo1 $(P<0.05)$ (Figure $2 \mathrm{~B})$. Moreover, $\alpha \mathrm{MSH}$ decreased the mRNA levels of M1 makers $C D 11 \mathrm{c}$ and $T N F \alpha(P<0.05)$, increased the levels of M2 makers $C D 206$ and $C D 163(P<0.05)$, and pAd-Foxo1 treatment

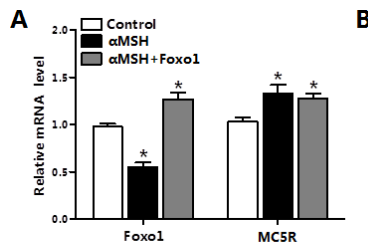

D

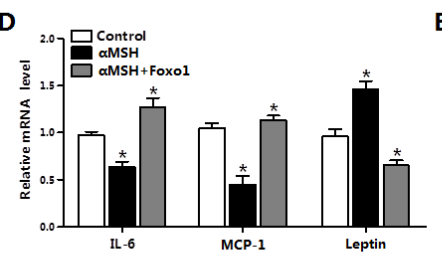

G

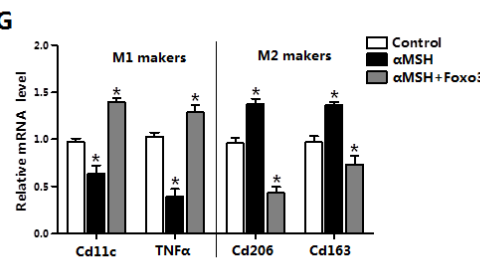

J

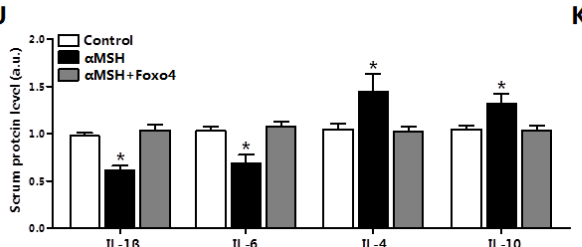

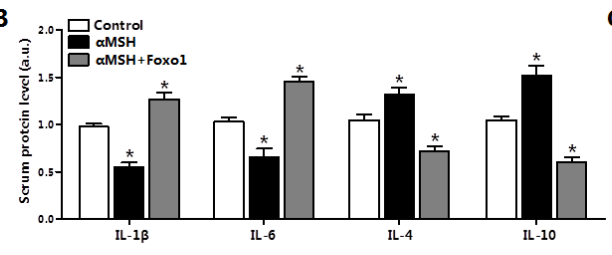

E ${ }_{2.0} \square_{\alpha \mathrm{MSH}}^{\text {Control }}$

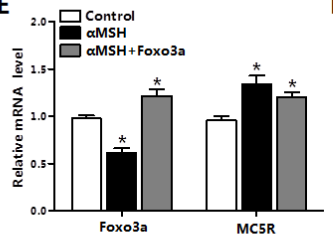

H

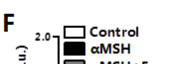

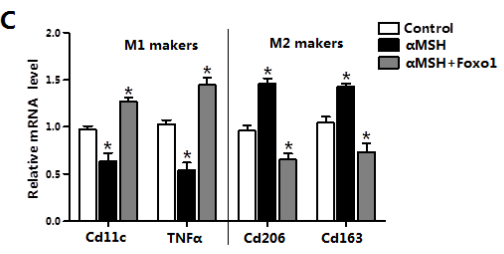

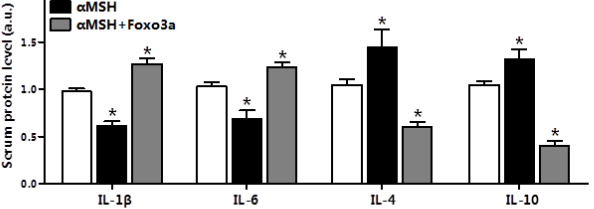

I

I 2.07 Control

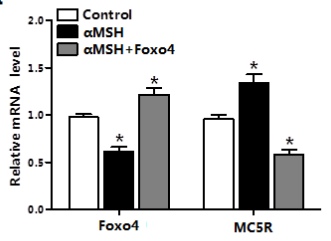

L

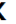

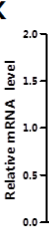

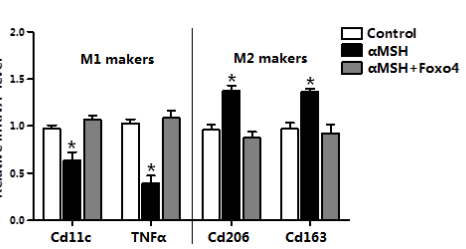

L

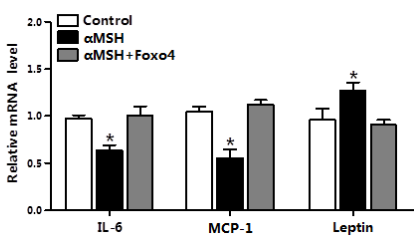

Figure 2: FoxOs reverse the inhibition of $\alpha \mathrm{MSH}$ on adipose inflammation in mice. Mice white adipose tissue was isolated after intraperitoneal injection with pAd-Foxo1 and with another $500 \mathrm{nM} \alpha \mathrm{MSH}$, then mRNA levels of Foxo1, MC5R (A), M1, M2 markers (C), IL-6, MCP-1, Leptin (D) were measured (n=6). After intraperitoneal injection with pAd-Foxo1 and with another $500 \mathrm{nM} \alpha \mathrm{MSH}$, serum protein levels of IL-1 $\beta$, IL-6, IL-4 and IL-10 (B) were detected $(n=6)$. After intraperitoneal injection with pAd-Foxo3a and with another 500 $\mathrm{nM} \alpha \mathrm{MSH}$ to mice, mRNA levels of Foxo3a, MC5R (E), M1, M2 markers (G), IL-6, MCP-1, Leptin (H) were measured in white adipose tissue $(n=6)$. Serum protein levels of IL-1 $\beta$, IL-6, IL-4 and IL-10 $(\mathbf{F})$ were also detected $(n=6)$. Mice were intraperitoneal injected with pAdFoxo4 and another $500 \mathrm{nM} \alpha \mathrm{MSH}$, serum protein levels of IL-1 $\beta$, IL-6, IL-4 and IL-10 (J) and mRNA levels of Foxo4, MC5R (I), M1, M2 markers (K), IL-6, MCP-1, Leptin $(\mathbf{L})$ were measured $(\mathrm{n}=6)$. Values are means $\pm \mathrm{SD}$. vs. control group, ${ }^{*} P<0.05$. 
reversed the effects $(P<0.05)$ (Figure 2C). Notably, Foxo1 overexpression inverted the decrease of IL- 6 and $M C P I$ mRNA levels, and the increase of Leptin level stimulated by $\alpha \mathrm{MSH}(P<0.05)$ (Figure $2 \mathrm{D})$. To determine whether other factors of FoxOs in adipose tissue have same effects, we also measured mRNA or serum protein level of inflammation factors, M1 makers and M2 makers after treating with pAd-Foxo3a and pAd-Foxo4, respectively. We observed Foxo3a and Foxo4 also reversed the inhibitory effects of $\alpha \mathrm{MSH}$ on adipose inflammation, and the trend was same with Foxol (Figure 2E-2L). These data collectively suggested that Foxo1, Foxo3a and Foxo4 abolished the inhibition of $\alpha \mathrm{MSH}$ on adipose inflammation in mice.

\section{FoxOs abolish the suppression of $\alpha \mathrm{MSH}$ on inflammation in mice adipocytes}

Red $\mathrm{O}$ staining revealed that $\alpha \mathrm{MSH}$ inhibited adipocyte differentiation, coordinated with triglycerides (TG) decreased and free fatty acid (FFA) increased
$(P<0.05)$ (Figure 3A). In differentiated adipocytes, $\alpha \mathrm{MSH}$ elevated mRNA levels of its receptor MC5R and Leptin $(P<0.05)$, while reduced the mRNA levels of $I L-6, M C P-1$, TNF $\alpha$, Foxo1, Foxo3a and Foxo4 in adipocytes $(P<0.05)$ (Figure 3B-3D). Western blot analysis showed Foxo1 overexpression reversed the increased protein levels of Leptin and the deceased protein levels of Foxo1, IL-6, MCP-1 and TNF $\alpha$ treated by $\alpha \mathrm{MSH}(P<0.05)$ (Figure $3 \mathrm{~F})$. To determine which signal pathway is involved in this process, we measured the phosphorylation level of Akt in adipocytes. We observed that $\alpha \mathrm{MSH}$ significantly decreased Akt phosphorylation level $(P<0.05)$ (Figure $3 \mathrm{E}$ ), which is consistent with our previous findings that activation of Akt 2 signal blunted RES inhibitory adipose inflammation [32]. Moreover, Foxo3a rescued the decreases of Foxo3a, IL-6 and p-Akt ${ }^{\mathrm{Ser} 473}$ protein levels treated with $\alpha \mathrm{MSH}(P<0.05)$ (Figure $3 \mathrm{G})$. Furthermore, Foxo4 only reversed the upregulation of MC5R and Leptin $(P<0.05)$, and the downregulation of Foxo 4 and $I L-6$ by $\alpha \mathrm{MSH}$ in mRNA level $(P<0.05)$ (Figure $3 \mathrm{H})$, suggesting that $\alpha \mathrm{MSH}$ may inhibit adipocyte inflammation partly via
A

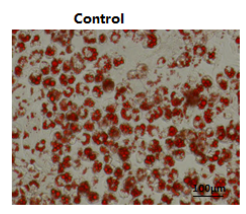

C

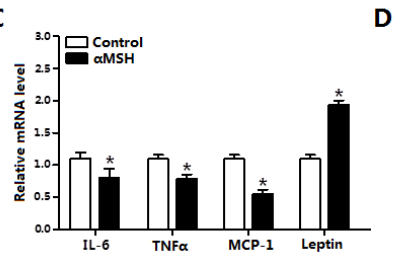

aMSH

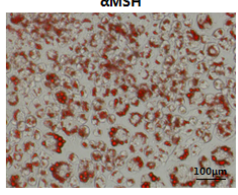

D

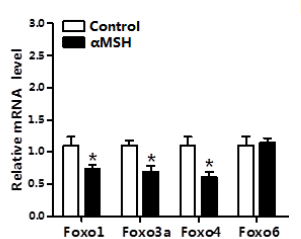

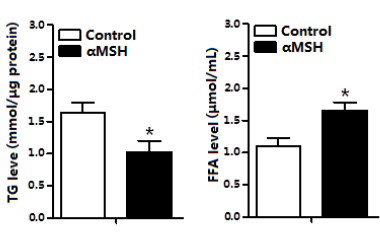

E

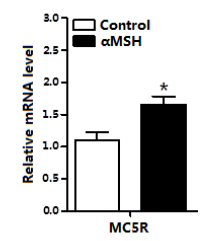

F
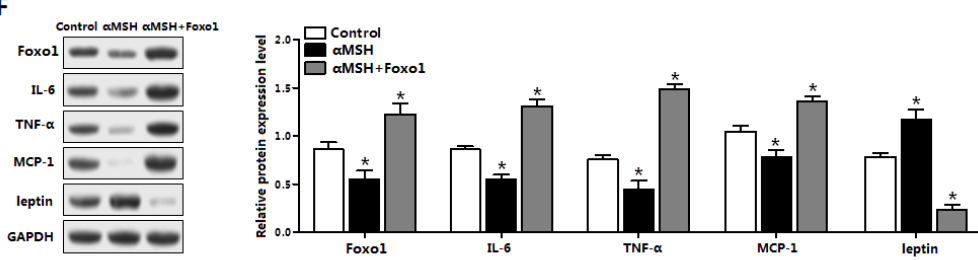

G
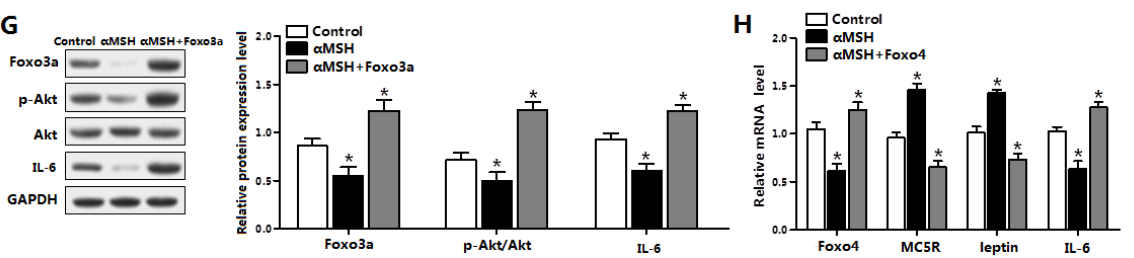

Figure 3: FoxOs abolish the suppression of $\alpha$ MSH on inflammation in mice adipocytes. (A) Oil Red O staining for differentiated primary adipocytes isolated from epididymal white adipose tissue after administration of $\alpha \mathrm{MSH}$ for $1 \mathrm{~h}$ (left). Relative concentration of TG in adipocytes (middle) and FFA in cell culture medium (right) were detected ( $\mathrm{n}=3$ ). With $\alpha \mathrm{MSH}$ treatment, mRNA levels of MC5R (B), IL-6, TNF, MCP-1 and Leptin (C), Foxo1, Foxo3a, Foxo4 and Foxo6 (D), protein levels of p-AKT and total Akt (E) were detected in adipocytes $(\mathrm{n}=3)$. (F) Adipocytes treated with pAd-Foxo1 and $\alpha$ MSH, protein levels of IL-6, TNF $\alpha$, MCP-1 and Leptin were measured ( $\mathrm{n}=3)$. (G) Expression levels for Foxo3a, p-Akt, Akt and IL-6 protein after cells treated with pAd-Foxo3a and $\alpha \mathrm{MSH}(\mathrm{n}=3)$. (H) Normalized mRNA levels of Foxo4, MC5R, Leptin and $I L-6$ with pAd-Foxo4 and $\alpha \mathrm{MSH}$ treatments (n=3). Values are means \pm SD. vs. control group, $* P<0.05$. 
Foxo4 transcriptional regulation. These data indicated that Foxo1, Foxo3a and Foxo4 abolished the inhibition of $\alpha \mathrm{MSH}$ on inflammation in mice adipocytes.

\section{Foxo1 and Foxo3a reverse the inhibition of $\alpha$ MSH on LPS-induced inflammation in mice adipocytes}

After $24 \mathrm{~h}$ and $48 \mathrm{~h}$ administration for LPS, live adipocytes number were significantly declined $(P<0.05)$ (Figure 4A). LPS strikingly reduced the mRNA levels of MC5R and Leptin $(P<0.05)$, while increased the levels of $I L-6$, Foxo1, Foxo3a and Foxo4 $(P<0.05)$, but did not change the expression of Caspase3, implying no adipocyte apoptosis occurrence (Figure 4B). LPS promoted the mRNA levels of $I L-6$ and $M C P$ $1(P<0.05)$, and inhibited Leptin mRNA expression $(P<0.05)$ (Figure $4 \mathrm{C}$ and 4D). Furthermore, $\alpha \mathrm{MSH}$ significantly decreased the mRNA levels of $I L-6$ and MCP-1 $(P<0.05)$, increased the level of Leptin $(P<0.05)$, but these effects were abolished by Foxo1 or Foxo3a $(P<0.05)$ (Figure 4C and 4D). Together, these results revealed that $\alpha \mathrm{MSH}$ can finely block the LPS induced inflammation and Foxo1, Foxo3a reversed the antiinflammatory function of $\alpha \mathrm{MSH}$ in mice adipocytes.

\section{Foxo4 attenuates MC5R transcription in $\alpha$ MSH inhibited inflammation in mice adipocytes}

To explore how Foxo4 influence the transcription of MC5R in aMSH inhibited inflammation, we detected the binding affinity between Foxo4 and MC5R promoter. Luciferase assay was carried out after co-transfection of Foxo4 overexpression vector and plasmid with different MC5R 5'regions in HEK393T cells, and results showed that the luciferase activity of MC5R was declined on the sites of $-1200,-680,-400 \mathrm{bp}$, but not $-210 \mathrm{bp}$ when Foxo4 overexpressed $(P<0.05)$ (Figure 5A). Enrichment of Foxo4 also significantly increased in Foxo4 overexpressed group $(P<0.05)$ (Figure 5B), suggesting that Foxo4 binds to MC5R promoter. LPS inhibited $M C 5 R$ mRNA expression $(P<0.05)$, however, $\alpha \mathrm{MSH}$ treatment or overexpressed MC5R plasmid transfection both significantly increased MC5R level in non LPS and LPS-induced condition $(P<0.05)$, and these effects was reversed by Foxo4 overexpression $(P<0.05)$ (Figure 5C
A

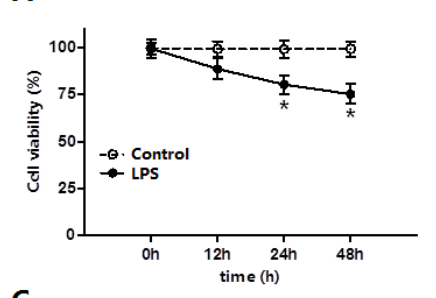

B

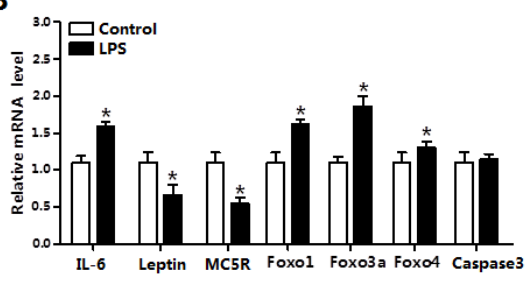

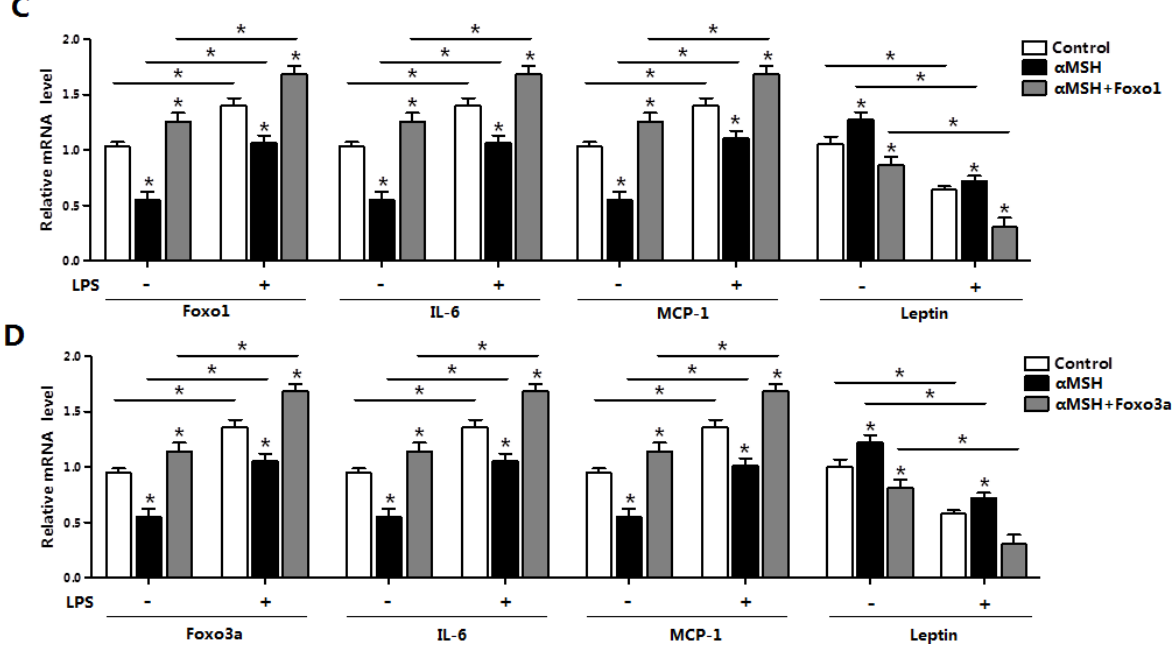

Figure 4: Foxo1 and Foxo3a reverse the inhibition of $\alpha$ MSH on LPS-induced inflammation in mice adipocytes. (A) Primary adipocytes were cultured and incubated for $0 \mathrm{~h}, 12 \mathrm{~h}, 24 \mathrm{~h}$ and $48 \mathrm{~h}$ in the presence of $1 \mu \mathrm{g} / \mathrm{mL}$ LPS. Cell viability was detected by CCK-8 (n=3). (B) Relative mRNA expressions of IL-6, Leptin, MC5R, Foxo1, Foxo3a, Foxo4, Foxo6 and Caspase 3 with $\alpha$ MSH treatment were analyzed $(\mathrm{n}=3)$. (C) After adipocytes treated with pAd-Foxol and incubated for LPS/saline and $\alpha \mathrm{MSH}$, mRNA levels of Foxol, $I L-6, M C P-1$ and Leptin were detected (n=3). (D) Adipocytes were treated with pAd-Foxo3a and incubated for LPS/saline and $\alpha \mathrm{MSH}$, then measured mRNA levels of Foxo3a, IL-6, MCP-1 and Leptin (n=3). Values are means \pm SD. vs. control group, ${ }^{*} P<0.05$. 
and 5D). LPS significantly increased the mRNA levels of Foxo4, IL-6, TNF $\alpha$ and MCP-1 $(P<0.05)$, decreased the level of Leptin $(P<0.05)$ (Figure 5E). $\alpha \mathrm{MSH}$ decreased the mRNA levels of Foxo4, IL-6, TNF $\alpha$ and $M C P-1(P<0.05)$, increased the level of Leptin $(P<0.05)$, but Foxo4 reversed the effects $(P<0.05)$ (Figure $5 \mathrm{E}$ ). These data suggested that $\alpha \mathrm{MSH}$ inhibited LPS-induced inflammation in mice adipocytes through Foxo4 negative transcription on MC5R promoter.

\section{Akt/JNK signal pathway is impaired in the inhibition of $\alpha$ MSH on adipocyte inflammation and FoxOs expressions}

To further elucidate molecular mechanism in $\alpha \mathrm{MSH}$ inhibited adipocyte inflammation, we analyzed the major inflammatory pathways in adipose tissue. Figure $6 \mathrm{~A}$ showed $\alpha \mathrm{MSH}$ treatment in adipocytes decreased the phosphorylation level of $\mathrm{Akt}^{\mathrm{Ser} 473}$ and $\mathrm{JNK}^{\mathrm{Thr} 183}$
A

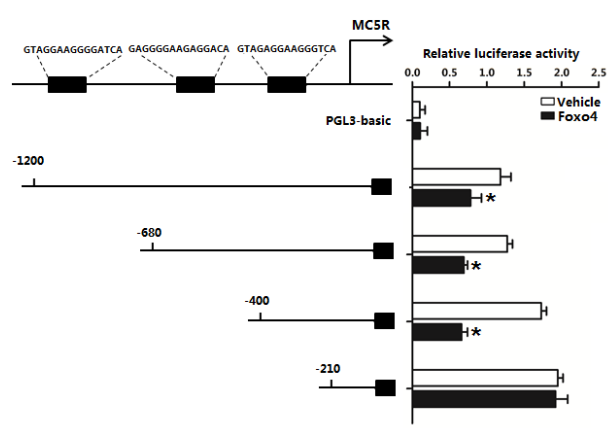

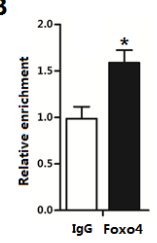

C
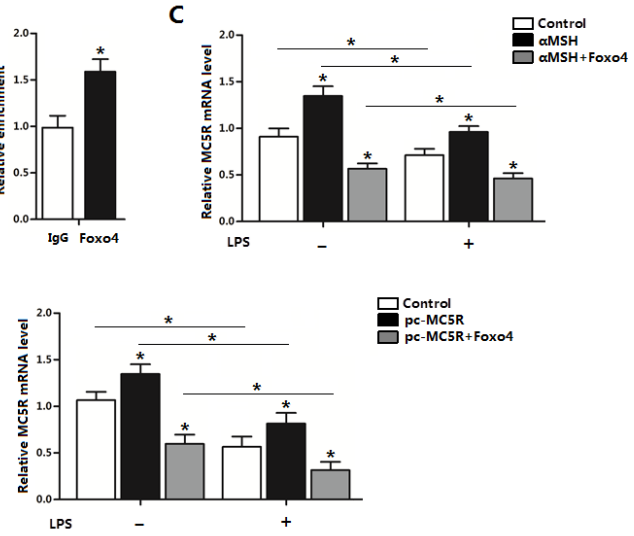

$\mathrm{E}$

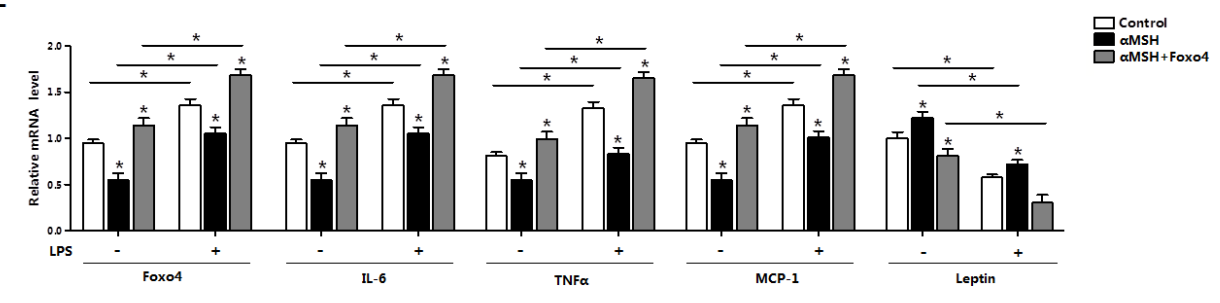

Figure 5: Foxo4 negatively regulate MC5R transcription in $\alpha$ MSH inhibited inflammation in mice adipocytes. (A) Fragments of MC5R promoter fused to a luciferase reporter plasmid or PGL3-basic (control) were co-transfected into cells together with Renlilla plasmid and pAd-Foxo4 $(\mathrm{n}=3)$. Luciferase activity was corrected for Renilla luciferase activity and normalized to control activity $(\mathrm{n}=3)$. (B) Chromatin immunoprecipitation (ChIP) analysis of Foxo4 and MC5R interaction. (C, D) After pAd-Foxo4 together with $\alpha \mathrm{MSH}$ or pc-MC5R in LPS/saline treatment, $M C 5 R$ mRNA level was determined in adipocytes $(\mathrm{n}=3)$. $(\mathbf{E})$ When adipocytes were treated with pAd-Foxo4 and $\alpha$ MSH in LPS/saline treatment, mRNA levels of Foxo4, IL-6, TNF,$M C P-1$ and Leptin were analyzed (n=3). Values are means $\pm \mathrm{SD}$. vs. control group, ${ }^{*} P<0.05$.
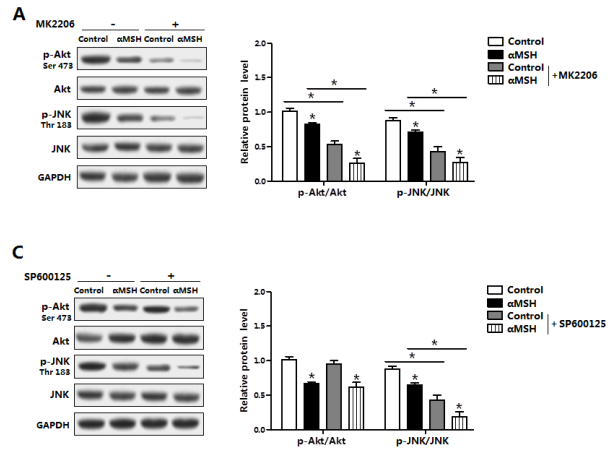
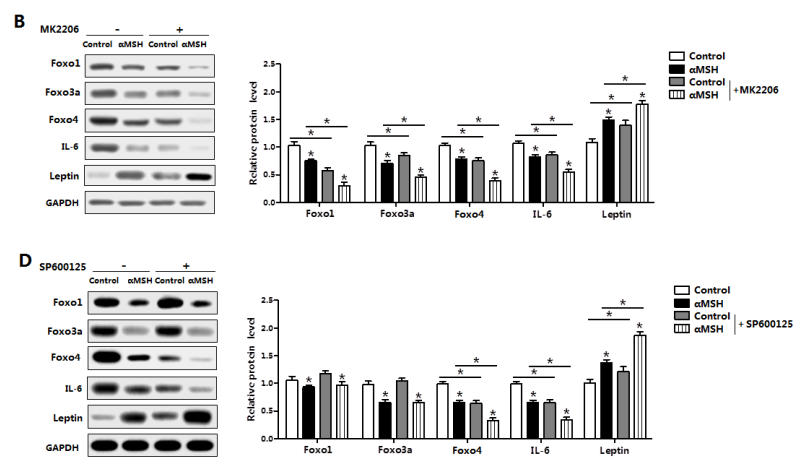

Figure 6: Akt/JNK signal pathway is impaired in the inhibition of aMSH on adipocyte inflammation and FoxOs expressions. Mouse adipocytes were pretreated with $\alpha \mathrm{MSH}$ and MK-2206 or SP600125, respectively. Relative protein levels of Akt, p-Akt ${ }^{\text {ser473 }}$, JNK, p-JNK ${ }^{\text {Thr183 }}$ (A), Foxo1, Foxo3a, Foxo4, IL-6 and Leptin (B) with or without MK-2206 (n=3). Representative immunoblots and densitometric quantification for Akt, p-Akt ${ }^{\text {ser473 }}$, JNK, p-JNK ${ }^{\text {Thr183 }}$ (C), Foxo1, Foxo3a, Foxo4, IL-6 and Leptin protein (D) with or without SP600125 $(n=3)$. The level of total GAPDH was used as the loading control. Values are mean \pm SD. $* P<0.05$ compared with the control. 
$(P<0.05)$. When the special Akt inhibitor MK-2206 was added, phosphorylation levels of $\mathrm{Akt}^{\mathrm{Ser} 473}$ and $\mathrm{JNK}^{\mathrm{Thr} 183}$ were correspondingly decreased $(P<0.05)$, and $\alpha \mathrm{MSH}$ treatment further decreased these protein levels $(P<0.05)$ (Figure 6A), which agree with our previous study that the Akt2 pathway was significantly activated when adipose inflammation happened [32]. The addition of $\alpha \mathrm{MSH}$ also aggravated the elevation on Leptin protein level and the inhibition of Foxo1, Foxo3a, Foxo4 and IL-6 treated with MK-2206 $(P<0.05)$ (Figure 6B). To further identify whether other signaling pathways regulating adipocyte inflammation may exist downstream of Akt, we used the special JNK inhibitor SP600125 to treat cells. We observed that SP600125 significantly inhibited phosphorylation of $\mathrm{JNK}^{\mathrm{Thr} 183}(P<0.05)$, but had no effects on phosphorylation of $\mathrm{Akt}^{\mathrm{Ser} 473}$ (Figure 6C), suggesting that JNK signaling pathway may act downstream of Akt pathway, which is coherent with previous findings [33]. In addition, SP600125 decreased the protein levels of Foxo4 and IL-6 $(P<0.05)$, increased Leptin protein level $(P<0.05)$, but had no effects on the expressions of Foxol and Foxo3a (Figure 6D). $\alpha \mathrm{MSH}$ further reduced the protein levels of p-Akt ${ }^{\mathrm{Ser} 473}$, p-JNK ${ }^{\mathrm{Thr} 183}$, Foxo4 and IL-6 $(P<0.05)$, while promoted Leptin protein level $(P<0.05)$ (Figure 6C and $6 \mathrm{D})$. This revealed that Foxo4 but not Foxo1 and Foxo3a reversed the effects of $\alpha \mathrm{MSH}$ on adipocyte inflammation through JNK pathway. Thus, these data supported that $\alpha \mathrm{MSH}$ inhibited adipocyte inflammation by blocking Akt/ JNK signaling pathway and FoxOs expressions.

\section{DISCUSSION}

$\alpha \mathrm{MSH}$ as a tridecapeptide derived from POMC displays potent anti-inflammatory role in many tissues and has protective effects on therapies in brain damage, liver or lung fibrosis, skin inflammation and chronic adipose inflammation. The fusion protein TAT-HSA$\alpha-\mathrm{MSH}$ inhibits NF- $\kappa \mathrm{B}$ activation in human and TNF $\alpha$ production in mice to prevent brain inflammation in central nervous system (CNS) disorders [34, 35]. $\alpha \mathrm{MSH}$ has also been confirmed to inhibit antigen-induced allergic skin inflammation, abolish monocytes adhesion to vascular endothelium, attenuate bleomycin-induced pulmonary inflammation, blunt adipose oxidative stress and inflammation, and protect from adipose tissue apoptosis and fat deposition [24, 36-40]. In the present study we illustrated that $\alpha \mathrm{MSH}$ could blunt LPS-induced adipose inflammation, accompany with increased antiinflammatory cytokines expressions and decreased proinflammatory cytokines expressions. Moreover, $\alpha \mathrm{MSH}$ attenuated adipose inflammation in mice by inhibiting FoxOs expressions. Although Jun et al. reported that $\alpha \mathrm{MSH}$ in addition to Adrenocorticotropic hormone $(\mathrm{ACTH})$ promotes adipocyte inflammation by cytokine IL-6 production [41], most studies confirmed that $\alpha \mathrm{MSH}$ resists to adipose inflammation by releasing antiinflammatory factors and balancing metabolic rate $[24,42$, 43], which are consistent with our findings.

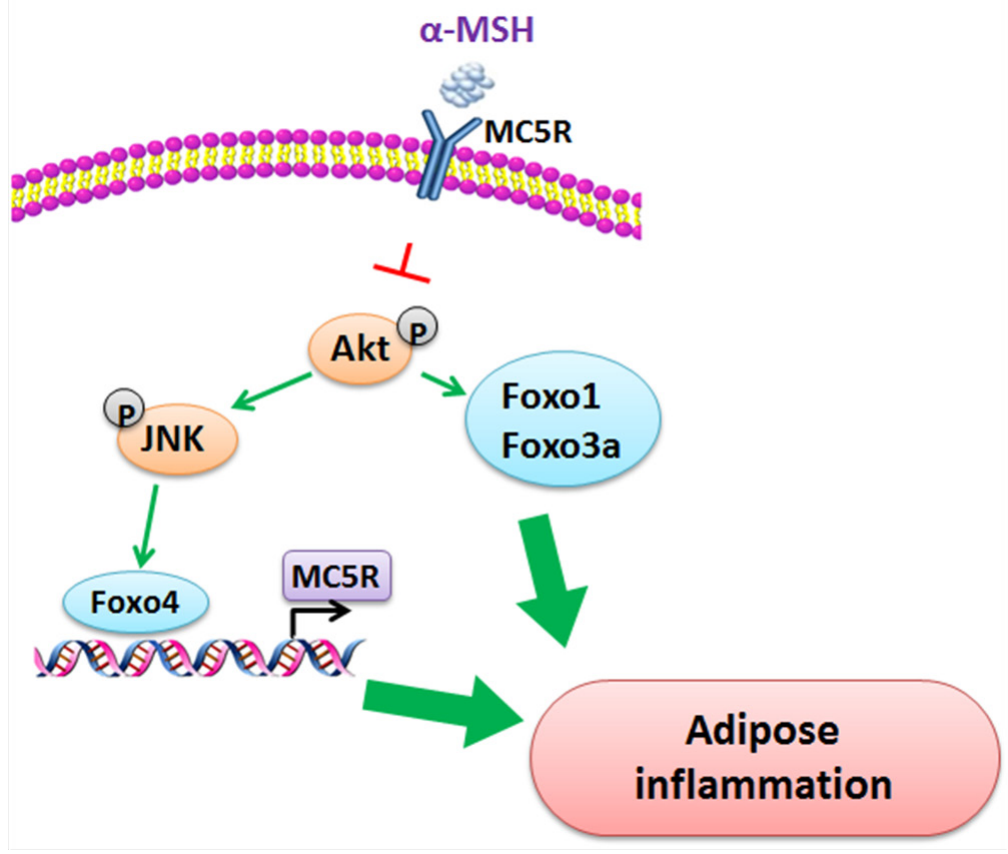

Figure 7: Proposed mechanism of the inhibition of $\alpha \mathrm{MSH}$ on adipose inflammation. $\alpha \mathrm{MSH}$ decreases adipose inflammation via blunting the phosphorylation of Akt/JNK. Akt phosphorylation activates Foxol and Foxo3a, while JNK phosphorylation activates Foxo4. What is more, Foxo4 acts via binding the promoter of MC5R, which is the receptor of $\alpha \mathrm{MSH}$. 
Table 1: Primers for real-time PCR

\begin{tabular}{|c|c|c|}
\hline Genes & Accession number & Primer sequences ( $5^{\prime}$ to $\left.3^{\prime}\right)$ \\
\hline \multirow[t]{2}{*}{ CD11c } & NM_021334.2 & F: ATGATAGTTCCTGGGTGGTGGTTGG \\
\hline & & R: AGAGAACTGCATCAGGGAGAACCGT \\
\hline \multirow[t]{2}{*}{$\mathrm{TNF} \alpha$} & NM_013693.3 & F: ACGGCATGGATCTCAAAGAC \\
\hline & & R: CGGCAGAGAGGAGGTTGACT \\
\hline \multirow[t]{2}{*}{ CD206 } & NM_008625.2 & F: CTCTGTTCAGCTATTGGACGC \\
\hline & & R: TGGCACTCCCAAACATAATTTGA \\
\hline \multirow[t]{2}{*}{ CD163 } & NM_001170395.1 & F: GGTGGACACAGAATGGTTCTTC \\
\hline & & R: CCAGGAGCGTTAGTGACAGC \\
\hline \multirow[t]{2}{*}{ MC5R } & NM_013596.2 & F: CAAGACCAGAGCCCGGTAAAC \\
\hline & & R: GCGCAAAGGTAAGCATGATTCT \\
\hline \multirow[t]{2}{*}{ IL-6 } & NM_031168.2 & F: AGACAAAGCCAGAGTCCTTCAG \\
\hline & & R: TGCCGAGTAGATCTCAAAGTGA \\
\hline \multirow[t]{2}{*}{ MCP-1 } & NM_011333.3 & F: CACAACCACCTCAAGCAC \\
\hline & & R: AAGGGAATACCATAACATCA \\
\hline \multirow[t]{2}{*}{ Leptin } & NM_008493.3 & F: GAAGCGTCTCGGGATCTCTG \\
\hline & & R: CAGGATCAATGACATTTCACACA \\
\hline \multirow[t]{2}{*}{ Caspase 3} & NM_009810 & F: CTCGCTCTGGTACGGATGTG \\
\hline & & R: TCCCATAAATGACCCCTTCATCA \\
\hline \multirow[t]{2}{*}{ Foxo1 } & NM_019739.3 & F: GGACAGCCGCGCAAGACCAG \\
\hline & & R: TTGAATTCTTCCAGCCCGCCGA \\
\hline \multirow[t]{2}{*}{ Foxo3a } & NM_019740.2 & F: GTGGACCGACTTCCGCTCGC \\
\hline & & R: GCTTGCCAGGATGGGCGACA \\
\hline \multirow[t]{2}{*}{ Foxo4 } & NM_018789.2 & F: ACTTTGAGCCAGATCCCTGAGTCAC \\
\hline & & R: TAAGGACAGGCCTGGCTCCACC \\
\hline \multirow[t]{2}{*}{ Foxo6 } & NM_194060.1 & F: GTGGGGGAACCTTTCCTACG \\
\hline & & R: TTCTGCACGCGGATGAACC \\
\hline \multirow[t]{2}{*}{ GAPDH } & NM_001289726.1 & F: AGGTCGGTGTGAACGGATTTG \\
\hline & & R: TGTAGACCATGTAGTTGAGGTCA \\
\hline
\end{tabular}

FoxOs in mammals are important transcription factors in regulating adipose inflammation. Our results showed a significant increase of mRNA levels of Foxo1, Foxo3a and Foxo4 in adipose tissue induced by LPS, but had no effects on Foxo6, so we focused on the effects of Foxo1, Foxo3a and Foxo4 on $\alpha \mathrm{MSH}$ inhibited adipose inflammation. Studies have shown that phosphorylation of Foxol and $\mathrm{Akt}^{\mathrm{Ser} 473}$ is activated in endothelial nitric oxide synthase (eNOS) production, which promotes adipose inflammatory reaction [44]. Pdk1-Foxo1 signaling also contributes to adipose inflammation and insulin resistance [45]. For Foxo3a, it has been reported that SIRT1-FoxO3A axis acts on autophagy activation in macrophages [46] and Foxo3a is also required in inflammation to prevent Fas ligand-induced neutrophil apoptosis [47]. Our results proved that Foxo1 and Foxo3a both aggravated LPSinduced inflammation in mice adipocytes, plus Foxo1, Foxo3a and Foxo4 reversed the inhibition of $\alpha \mathrm{MSH}$ on adipose inflammation in vivo and in vitro. For another, Foxo4 is confirmed to be the center of a transcriptional regulatory network that links gene transcription required for many inflammatory cytokine signals [29, 48, 49]. We showed here Foxo4 negatively regulated MC5R promoter transcription, which brought to the abolition 
of aMSH's anti-inflammation effects. These results demonstrate FoxOs are aggressive factors in adipose tissue inflammation. When further study the signal pathway which $\alpha \mathrm{MSH}$ interacts with, we examined the influence of Akt/JNK signal pathway, a key pathway in adipose inflammation [32]. Our study revealed that $\alpha \mathrm{MSH}$ could blunt the phosphorylation of Akt/JNK and specifically, Akt phosphorylation activates Foxo1 and Foxo3a, while JNK phosphorylation stimulates Foxo4. In addition, Foxo4 acts via binding the promoter of MC5R, which is the receptor of $\alpha \mathrm{MSH}$. (Figure 7). These findings are coherent with the previous study, which show FoxOs are required for Akt activity and JNK signaling pathway in systemic inflammation and cells survival $[50,51]$.

In summary, our study provided a new insight into the mechanisms of $\alpha \mathrm{MSH}$ on adipose inflammation. We identified that $\alpha \mathrm{MSH}$ inhibited adipose inflammation by inhibiting Akt and JNK signaling pathway and FoxOs expressions. Moreover, we found that Foxo4 was a novel transcriptional factor of MC5R in aggravating adipose inflammation. These results will be valuable for prevention and treatment of inflmmatory diseases.

\section{MATERIALS AND METHODS}

\section{Animal experiments}

Two-week-old male Kunming mice were purchased from the Laboratory Animal Center of the Fourth Military Medical University. All mice were treated in accordance with the applicable guidelines and regulations approved by the Animal Ethics Committee of Northwest A\&F University. They were allowed ad libitum access to water and standard chow laboratory diet. The animal room was maintained in controlled conditions of temperature at $25 \pm 1{ }^{\circ} \mathrm{C}$, humidity at $55 \pm 5 \%$, and a $12 \mathrm{~h}$ light/12 h dark cycle. Body weight was recorded once a week. After intraperitoneal injection of pAd-Foxo1, pAd-Foxo3a, pAd-Foxo4 for $10 \mathrm{~d}$ and 500 $\mathrm{nM} \alpha \mathrm{MSH}$ pre-treated for $1 \mathrm{~h}$, mice were euthanized for collection of tissues and blood.

\section{Primary cell culture}

Epididymal white adipose tissues were harvested from four-week-old mice, visible fibers and blood vessels were removed, and the adipose tissue was washed three times with PBS buffer containing $200 \mathrm{U} / \mathrm{mL}$ penicillin (Sigma) and $200 \mathrm{U} / \mathrm{mL}$ streptomycin (Sigma). The adipose tissue was minced into fine sections $\left(1 \mathrm{~mm}^{3}\right)$ and incubated in $10 \mathrm{~mL}$ digestion buffer containing DMEM/F-12 (Gibco), 100 mM HEPES (Sigma), 1.5\% BSA (Sigma), and $2 \mathrm{mg} / \mathrm{mL}$ type I collagenase (Sigma) for $50 \mathrm{~min}$ at $37{ }^{\circ} \mathrm{C}$ water bath. After the incubation, growth medium [DMEM/F-12 (50:50)], 10\% fetal bovine serum (Sigma), $100 \mathrm{U} / \mathrm{mL}$ penicillin, and $100 \mathrm{U} / \mathrm{mL}$ streptomycin were added to the digestion flask. Flask contents were mixed and filtered through nylon screens with $250 \mu \mathrm{m}$ and
$20 \mu \mathrm{m}$ meshes to remove undigested tissue and large cell aggregates. The filtered cells were centrifuged at 1300 rpm for $7 \mathrm{~min}$ to separate floating adipocytes from cell pellets. Isolated cell pellets were suspended in DMEM/ F12 (Invitrogen). Finally, cells were seeded into $35 \mathrm{~mm}$ primary culture dishes at a density of $8 \times 10^{4}$ cells/dish and incubated at $37{ }^{\circ} \mathrm{C}$ under a humidified atmosphere of $5 \%$ $\mathrm{CO}_{2}$ and $95 \%$ air until confluence.

\section{Chemical treatment and transfection}

The recombinant adenovirus overexpression vector of Foxo1 (pAd-Foxo1), recombinant adenovirus overexpression vector of Foxo3a (pAd-Foxo3a), recombinant adenovirus overexpression vector of Foxo4 (pAd-Foxo4), recombinant adenovirus overexpression vector of Foxo6 (pAd-Foxo6) and overexpression plasmid vector of MC5R (pc-MC5R) were constructed in our lab. When primary adipocytes were plated at a concentration of $1 \times 10^{5}-1 \times 10^{6} / \mathrm{ml}$ in 60 $\mathrm{mm}$ dish (suspension cells), these recombinant adenovirus vectors were respectively mixed with Opti-MEMI media (Invitrogen) and X-treme GENE HP Reagent (Roche, Switzerland), then the mixture were added to each culture dishes afterwards. The $\alpha$ MSH (Sigma, St. Louis, MO, USA) and the working solution $(500 \mathrm{nM})$ were mixed to treat adipocytes for $1 \mathrm{~h}$. Cells were collected for Real-time PCR after $24 \mathrm{~h}$ infection and for Western blot after $48 \mathrm{~h}$.

On the fourth day of cell differentiation, cells were treated with $10 \mu \mathrm{M}$ Akt phosphorylation-specific inhibitor MK-2206 (MedChem Express, USA), $10 \mu \mathrm{M}$ JNK phosphorylation-specific inhibitor SP600125 (Selleck Chemical, USA), respectively. The $\alpha \mathrm{MSH}$ (Sigma, St. Louis, MO, USA) was added to adipocytes for $1 \mathrm{~h}$ before collecting for Western blot analysis.

\section{LPS-induced administration}

Inflammation model was established by intraperitoneal (i.p.) injection of LPS in $0.9 \%$ saline at a dose of $1 \mathrm{mg} / \mathrm{kg}$ of body weight in mice. Control mice were injected with saline only. Experiments were performed at $24 \mathrm{~h}$ after LPS administration.

In vitro, primary adipocytes isolated from eWAT were cultured to a concentration of $1 \times 10^{5}-1 \times 10^{6} / \mathrm{ml}$ in 60 $\mathrm{mm}$ dish, and then incubated with $1 \mu \mathrm{g} / \mathrm{mL}$ LPS. Control group was treated with PBS. Cell viability was measured after incubating for $0 \mathrm{~h}, 12 \mathrm{~h}, 24 \mathrm{~h}$ and $48 \mathrm{~h}$. Gene expression profile was analyzed at $24 \mathrm{~h}$ after LPS treatment.

\section{Oil red $O$ staining}

Lipid droplets were stained with Oil Red O staining as described in our previous publication [32]. Firstly, primary adipocytes were washed with PBS thrice, and then incubated in 4\% formaldehyde for 30 minutes at room temperature. Then cells were gently washed with PBS thrice, stained with Oil Red O (Sigma, St. Louis, USA) 
for $30 \mathrm{~min}$, and incubated at $37{ }^{\circ} \mathrm{C}$ temperature. Cells were washed in PBS for 3 times to remove unbounded dye, and then took photographs with Nikon TE2000-S florescent microscope. The stained fat droplets were dissolved in isopropanol and quantified by measuring the optical density at $510 \mathrm{~nm}$ using a spectrophotometer. Total protein content was measured with the DC assay (BioRad, USA) and triglycerides were analyzed by TG assay kit (Jiancheng, China). Free fatty acid (FFA) content was determined at absorption at $570 \mathrm{~nm}$ with a FFA assay kit (Jiancheng, China).

\section{ELISA assay}

Mice blood supernatants were collected and frozen at $-80{ }^{\circ} \mathrm{C}$. $\alpha \mathrm{MSH}$ content and serum protein levels of IL$1 \beta$, IL-4, IL-6 and IL-10 were measured using commercial ELISA kits (R\&D Systems, USA), the procedure was described previously [52].

\section{Real-time PCR}

Total RNA was extracted with TRIpure Reagent kit (Takara, China). $500 \mathrm{ng}$ of total RNA was reverse transcribed using M-MLV reverse transcriptase kit (Roche). Primers of CD11c, TNFa, CD206, CD163, MC5R, IL-6, MCP-1, Leptin, Foxo1, Foxo3a, Foxo4, Foxo6, Caspase3 and GAPDH were designed as Table 1 and synthesized by Invitrogen. Quantitative PCR was performed in $20 \mu \mathrm{L}$ reaction system containing specific primers, SYBR Premix EX Taq (Takara, China), cDNA and $\mathrm{ddH}_{2} \mathrm{O}$. The level of mRNA was normalized by $G A P D H$. The relative mRNA levels of genes were analyzed with the method of $2^{-\Delta \Delta \mathrm{Ct}}$.

\section{Immunoblot analysis}

Mouse adipocytes were solubilized in lysis buffer for $40 \mathrm{~min}$ at $4{ }^{\circ} \mathrm{C}$, then the solution was centrifuged at $12,000 \mathrm{~g}$ for $15 \mathrm{~min}$ at $4{ }^{\circ} \mathrm{C}$ and the supernatants were to determine protein concentration. In addition, protein samples $(30 \mu \mathrm{g})$ were separated by electrophoresis on $12 \%$ and 5\% SDS-PAGE gels using slab gel apparatus, and transferred to PVDF nitrocellulose membranes (Millipore, USA) blocked with 5\% skim milk powder/Tween 20/ TBST at room temperature for $2 \mathrm{~h}$. The membranes were then incubated with with primary antibodies in 5\% milk overnight at $4^{\circ} \mathrm{C}$. Foxo1 (ab52857), Foxo3a (ab17026), Foxo4 (ab63254), IL-6 (ab7737), TNFa (ab9739), MCP1 (ab25124), JNK (ab199380), JNK (Thr183) (ab47337) antibodies were purchased from Abcam (Cambridge, UK). Akt (BS1978), phospho-Akt (Ser473) (BS4006), GAPDH (Ap0063) antibodies were purchased from Bioworld (Nanjing, China). Leptin (sc-9014) was purchased from Santa Cruz Biotechnology (CA, USA). Followed, the appropriate HRP conjugated secondary antibodies (Boaoshen, China) were added and incubated for $2 \mathrm{~h}$ at room temperature. Proteins were visualized using chemiluminescent peroxidase substrate (Millipore), and then the blots were quantified using ChemiDoc XRS system (Bio-Rad, USA).

\section{Luciferase reporter assays}

Four fragments containing MC5R-5' sequences from -1200 to -210 relative to the transcription initiation site were sub-cloned into pGL3-basic vector (Takara, China). Luciferase reporter assay procedure was performed as previously described [53]. Briefly, HEK293T cells were cultured in 24-well plates. Cells were co-transfected with Foxo4 overexpression vector, Renilla plasmid and pGL3-MC5R plasmid. pGL3-basic vector was considered as control reporter. Cells were harvested $48 \mathrm{~h}$ after transfection, and detected using the Dual-Luciferase Reporter assay system (Promega, USA). Luciferase activity was obtained by an average of luciferase assay experiments at least three times.

\section{Statistical analysis}

Statistical calculations were performed with SAS v8.0 (SAS Institute, Cary, NC). The effects of experimental treatments were determined using the one-way ANOVA procedure. Comparisons among the means of individual treatments were made by Fisher's least significant difference (LSD) post hoc test once the ANOVA analysis showed a significant effect of these treatments. Data are presented as mean $\pm \mathrm{SD}$ and from three independent experiments. $* \mathrm{P}<0.05$ was considered to be significant.

\section{CONFLICTS OF INTEREST}

The authors declare no conflicts of interest associated with this manuscript.

\section{GRANT SUPPORT}

This work was supported by the grants from the Major National Scientific Research Projects (2015CB943102) and the National Nature Science Foundation of China (31572365).

\section{REFERENCES}

1. Kotas ME, Medzhitov R. Homeostasis, inflammation, and disease susceptibility. Cell. 2015; 160:816-827.

2. Brestoff JR, Artis D. Immune regulation of metabolic homeostasis in health and disease. Cell. 2015; 161:146-160.

3. Wernstedt Asterholm I, Tao C, Morley TS, Wang QA, Delgado-Lopez F, Wang ZV, Scherer PE. Adipocyte inflammation is essential for healthy adipose tissue expansion and remodeling. Cell Metab. 2014; 20:103-118. 
4. Liu L, Mei M, Yang S, Li Q. Roles of chronic low-grade inflammation in the development of ectopic fat deposition. Mediators Inflamm. 2014; 2014:418185.

5. Amano SU, Cohen JL, Vangala P, Tencerova M, Nicoloro SM, Yawe JC, Shen Y, Czech MP, Aouadi M. Local proliferation of macrophages contributes to obesity associated adipose tissue inflammation. Cell Metab. 2014; 19:162-171.

6. Bavia L, de Castro ÍA, Cogliati B, Dettoni JB, Alves VA, Isaac L. Complement C5 controls liver lipid profile, promotes liver homeostasis and inflammation in C57BL/6 genetic background. Immunobiology. 2016; 221:822-832.

7. Weisberg SP, McCann D, Desai M, Rosenbaum M, Leibel RL, Ferrante AW Jr. Obesity is associated with macrophage accumulation in adipose tissue. J Clin Invest. 2003; 112:1796-1808.

8. Schinzari F, Tesauro M, Cardillo C. Endothelial and perivascular adipose tissue abnormalities in obesityrelated vascular dysfunction: novel targets for treatment. J Cardiovasc Pharmacol. 2017; 69:360-368. doi: 10.1097/ FJC.0000000000000469.

9. Samuel VT, Shulman GI. The pathogenesis of insulin resistance: integrating signaling pathways and substrate flux. J Clin Invest. 2016; 126:12-22.

10. Ortega FJ, Fernández-Real JM. Inflammation in adipose tissue and fatty acid anabolism: when enough is enough! Horm Metab Res. 2013; 45:1009-1019.

11. Wei X, Song H, Yin L, Rizzo MG, Sidhu R, Covey DF, Ory DS, Semenkovich CF. Fatty acid synthesis configures the plasma membrane for inflammation in diabetes. Nature. 2016; 539:294-298.

12. Lawler HM, Underkofler CM, Kern PA, Erickson C, Bredbeck B, Rasouli N. Adipose Tissue Hypoxia, Inflammation and Fibrosis in Obese Insulin Sensitive and Obese Insulin Resistant Subjects. J Clin Endocrinol Metab. 2016; 101:1422-1428.

13. Snodgrass RG, Boß M, Zezina E, Weigert A, Dehne N, Fleming I, Brüne B, Namgaladze D. Hypoxia Potentiates Palmitate-induced Pro-inflammatory Activation of Primary Human Macrophages. J Biol Chem. 2016; 291:413-424.

14. Lumeng CN, DelProposto JB, Westcott DJ, Saltiel AR. Phenotypic switching of adipose tissue macrophages with obesity is generated by spatiotemporal differences in macrophage subtypes. Diabetes. 2008; 57:3239-3246.

15. Braune J, Weyer U, Hobusch C, Mauer J, Brüning JC, Bechmann I, Gericke M. IL-6 Regulates M2 Polarization and Local Proliferation of Adipose Tissue Macrophages in Obesity. J Immunol. 2017; 198:2927-2934. doi: 10.4049/ jimmunol.1600476.

16. Kaneda MM, Messer KS, Ralainirina N, Li H, Leem CJ, Gorjestani S, Woo G, Nguyen AV, Figueiredo CC, Foubert $\mathrm{P}$, Schmid MC, Pink M, Winkler DG, et al. PI3K $\gamma$ is a molecular switch that controls immune suppression. Nature. 2016; 539:437-442.
17. Cone RD. Anatomy and regulation of the central melanocortin system. Nature neuroscience. 2005; 8:571-578.

18. Shipp SL, Cline MA, Gilbert ER. Recent advances in the understanding of how neuropeptide $\mathrm{Y}$ and $\alpha$-melanocyte stimulating hormone function in adipose physiology. Adipocyte. 2016; 5:333-350.

19. Gómez-SanMiguel AB, Villanúa MÁ, Martín AI, LópezCalderón A. D-TRP(8)- $\gamma$ MSH Prevents the Effects of Endotoxin in Rat Skeletal Muscle Cells through TNFa/ NF-KB Signalling Pathway. PLoS One. 2016; 11:e0155645.

20. Lee SN, Ryu JH, Joo JH, Choi YH, Lee HJ, Kim YJ, Kim $\mathrm{KB}$, Yoon JH. $\alpha$-Melanocyte-stimulating hormone inhibits tumor necrosis factor $\alpha$-stimulated MUC5AC expression in human nasal epithelial cells. Am J Respir Cell Mol Biol. 2011; 44:716-724.

21. Cragnolini AB, Caruso C, Lasaga M, Scimonelli TN. Alpha-MSH and gamma-MSH modulate early release of hypothalamic PGE2 and NO induced by IL-1beta differently. Neurosci Lett. 2006; 409:168-172.

22. Cullberg KB, Larsen JØ, Pedersen SB, Richelsen B. Effects of LPS and dietary free fatty acids on MCP-1 in 3T3-L1 adipocytes and macrophages in vitro. Nutrition \& diabetes. 2014; 4:e113.

23. Martín AI, Gómez-SanMiguel AB, Gómez-Moreira C, Villanúa MÁ, López-Calderón A. $\alpha$ MSH blunts endotoxininduced MuRF1 and atrogin-1 upregulation in skeletal muscle by modulating NF- $\mathrm{BB}$ and Akt/FoxO1 pathway. Mediators Inflamm. 2014; 2014:179368.

24. Page S, Chandhoke V, Baranova A. Melanin and melanogenesis in adipose tissue: possible mechanisms for abating oxidative stress and inflammation? Obes Rev. 2011; 12:e21-31.

25. Mastronardi CA, Srivastava V, Yu WH, Dees WL, McCann SM. Lipopolysaccharide-induced leptin synthesis and release are differentially controlled by alpha-melanocytestimulating hormone. Neuroimmunomodulation. 2005; 12:182-188.

26. Gan L, Liu Z, Wu T, Feng F, Sun C. $\alpha$ MSH promotes preadipocyte proliferation by alleviating ER stress-induced leptin resistance and by activating Notch1 signal in mice. Biochim Biophys Acta. 2017; 1863:231-238.

27. Gan L, Liu Z, Chen Y, Dan Luo, Feng F, Liu G, Sun C. $\alpha-\mathrm{MSH}$ and Foxc2 promote fatty acid oxidation through $\mathrm{C} / \mathrm{EBP} \beta$ negative transcription in mice adipose tissue. Sci Rep. 2016; 6:36661.

28. Dejean AS, Hedrick SM, Kerdiles YM. Highly specialized role of Forkhead box O transcription factors in the immune system. Antioxid Redox Signal. 2011; 14:663-674.

29. Zhu M, Goetsch SC, Wang Z, Luo R, Hill JA, Schneider J, Morris SM Jr, Liu ZP. FoxO4 promotes early inflammatory response upon myocardial infarction via endothelial Arg1. Circ Res. 2015; 117:967-977. 
30. Bothur E, Raifer H, Haftmann C, Stittrich AB, Brüstle A, Brenner D, Bollig N, Bieringer M, Kang CH, Reinhard K, Camara B, Huber M, Visekruna A, et al. Antigen receptormediated depletion of FOXP3 in induced regulatory T-lymphocytes via PTPN2 and FOXO1. Nat Commun. 2016; 6:8576.

31. Kim DH, Park MH, Chung KW, Kim MJ, Park D, Lee B, Lee EK, Choi YJ, Kim ND, Yu BP, Chung HY. Suppression of FoxO6 by lipopolysaccharide in aged rat liver. Oncotarget. 2015; 6:34143-34157. doi: 10.18632/ oncotarget.6219.

32. Liu Z, Gan L, Liu G, Chen Y, Wu T, Feng F, Sun C. Sirt1 decreased adipose inflammation by interacting with Akt2 and inhibiting mTOR/S6K1 pathway in mice. J Lipid Res. 2016; 57:1373-1381.

33. Song Z, Zhang J, Zhang X, Li D, Wang H, Xu X, Xu W, Yin Y, Cao J. Interleukin 4 Deficiency Reverses Development of Secondary Pseudomonas aeruginosa Pneumonia During Sepsis-Associated Immunosuppression. J Infect Dis. 2015; 211:1616-1627.

34. Wang M, Zhi D, Wang H, Ru Y, Ren H, Wang N, Liu Y, Li Y, Li H. TAT-HSA-alpha-MSH fusion protein with extended half-life inhibits tumor necrosis factor-alpha in brain inflammation of mice. Appl Microbiol Biotechnol. 2016; 100:5353-5361.

35. Lasaga M, Debeljuk L, Durand D, Scimonelli TN, Caruso C. Role of alpha-melanocyte stimulating hormone and melanocortin 4 receptor in brain inflammation. Peptides. 2008; 29:1825-1835.

36. Etori M, Yonekubo K, Sato E, Mizukami K, Hirahara K, Karasuyama H, Maeda H, Yamashita M. Melanocortin receptors 1 and 5 might mediate inhibitory effects of alpha-melanocyte-stimulating hormone on antigen-induced chronic allergic skin inflammation in IgE transgenic mice. J Invest Dermatol. 2012; 132:1925-1927.

37. Yang Y, Zhang W, Meng L, Yu H, Lu N, Fu G, Zheng Y. Alpha-melanocyte stimulating hormone inhibits monocytes adhesion to vascular endothelium. Exp Biol Med (Maywood). 2015; 240:1537-1542.

38. Xu PB, Mao YF, Meng HB, Tian YP, Deng XM. STY39, a novel alpha-melanocyte-stimulating hormone analogue, attenuates bleomycin-induced pulmonary inflammation and fibrosis in mice. Shock. 2011; 35:308-314.

39. Della-Fera MA, Baile CA. Roles for melanocortins and leptin in adipose tissue apoptosis and fat deposition. Peptides. 2005; 26:1782-1787.

40. Fehm HL, Smolnik R, Kern W, McGregor GP, Bickel U, Born J. The melanocortin melanocyte-stimulating hormone/ adrenocorticotropin(4-10) decreases body fat in humans. J Clin Endocrinol Metab. 2001; 86:1144-1148.

41. Jun DJ, Na KY, Kim W, Kwak D, Kwon EJ, Yoon JH, Yea K, Lee H, Kim J, Suh PG, Ryu SH, Kim KT. Melanocortins induce interleukin 6 gene expression and secretion through melanocortin receptors 2 and 5 in 3T3-L1 adipocytes. J Mol Endocrinol. 2010; 44:225-236.

42. Lute B, Jou W, Lateef DM, Goldgof M, Xiao C, Piñol RA, Kravitz AV, Miller NR, Huang YG, Girardet C, Butler AA, Gavrilova O, Reitman ML. Biphasic effect of melanocortin agonists on metabolic rate and body temperature. Cell Metab. 2014; 20:333-345.

43. Mastronardi CA, Srivastava V, Yu WH, Dees WL, McCann SM. Lipopolysaccharide-induced leptin synthesis and release are differentially controlled by alpha-melanocytestimulating hormone. Neuroimmunomodulation. 2005; 12:182-188.

44. Sun X, Lin J, Zhang Y, Kang S, Belkin N, Wara AK, Icli B, Hamburg NM, Li D, Feinberg MW. MicroRNA-181b Improves Glucose Homeostasis and Insulin Sensitivity by Regulating Endothelial Function in White Adipose Tissue. Circ Res. 2016; 118:810-821.

45. Kawano Y, Nakae J, Watanabe N, Fujisaka S, Iskandar K, Sekioka R, Hayashi Y, Tobe K, Kasuga M, Noda T, Yoshimura A, Onodera M, Itoh H. Loss of Pdk1-Foxo1 Signaling in Myeloid Cells Predisposes to Adipose Tissue Inflammation and Insulin Resistance. Diabetes. 2012; 61:1935-1948.

46. Pun NT, Subedi A, Kim MJ, Park PH. Globular Adiponectin Causes Tolerance to LPS-Induced TNF- $\alpha$ Expression via Autophagy Induction in RAW 264.7 Macrophages: Involvement of SIRT1/FoxO3A Axis. PLoS One. 2015; 10:e0124636.

47. Jonsson H, Allen P, Peng SL. Inflammatory arthritis requires Foxo3a to prevent Fas ligand-induced neutrophil apoptosis. Nat Med. 2005; 11:666-671.

48. Chang B, Sang L, Wang Y, Tong J, Wang B. The role of FoxO4 in the relationship between alcohol-induced intestinal barrier dysfunction and liver injury. Int $\mathrm{J}$ Mol Med. 2013; 31:569-576.

49. Li H, Liang J, Castrillon DH, DePinho RA, Olson EN, Liu ZP. FoxO4 regulates tumor necrosis factor alphadirected smooth muscle cell migration by activating matrix metalloproteinase 9 gene transcription. Mol Cell Biol. 2007; 27:2676-2686.

50. Milan G, Romanello V, Pescatore F, Armani A, Paik JH, Frasson L, Seydel A, Zhao J, Abraham R, Goldberg AL, Blaauw B, DePinho RA, Sandri M. Regulation of autophagy and the ubiquitin-proteasome system by the FoxO transcriptional network during muscle atrophy. Nat Commun. 2015; 6:6670.

51. Grabiec AM, Angiolilli C, Hartkamp LM, van Baarsen LG, Tak PP, Reedquist KA. JNK-dependent downregulation of FoxO1 is required to promote the survival of fibroblast-like synoviocytes in rheumatoid arthritis. Ann Rheum Dis. 2015; 74:1763-1771. 
52. Liu Z, Gan L, Chen Y, Luo D, Zhang Z, Cao W, Zhou Z, Lin X, Sun C. Mark4 promotes oxidative stress and inflammation via binding to PPAR $\gamma$ and activating NF- $\mathrm{KB}$ pathway in mice adipocytes. Sci Rep. 2016; 6:21382.
53. Liu Z, Gu H, Gan L, Xu Y, Feng F, Saeed M, Sun C. Reducing Smad3/ATF4 was essential for Sirt1 inhibiting ER stressinduced apoptosis in mice brown adipose tissue. Oncotarget. 2017; 8:9267-9279. doi: 10.18632/oncotarget.14035. 